\title{
An Integrated Hybrid Methodology for Estimation of Absorptivity and Interface Temperature in Laser Transmission Welding
}

\section{Dhruva Kumar Goyal}

Indian Institute of Technology Ropar

\section{Ramsingh Yadav}

Indian Institute of Technology Ropar

Ravi Kant ( $\nabla$ ravi.kant@iitrpr.ac.in )

Indian Institute of Technology Ropar https://orcid.org/0000-0001-5414-4139

\section{Research Article}

Keywords: Laser transmission welding (LTW), Electrolytic iron powder (EIP), Absorptivity, Finite element model, Interface temperature, Inverse estimation

Posted Date: September 13th, 2021

DOl: https://doi.org/10.21203/rs.3.rs-745798/v1

License: (c) (i) This work is licensed under a Creative Commons Attribution 4.0 International License. Read Full License 


\title{
An integrated hybrid methodology for estimation of absorptivity and interface temperature in laser transmission welding
}

\author{
Dhruva Kumar Goyal, Ramsingh Yadav, Ravi Kant* \\ Department of Mechanical Engineering, Indian Institute of Technology Ropar, Rupnagar- \\ 140001, Punjab, India \\ *Corresponding Author: ravi.kant@iitrpr.ac.in
}

Mr. Dhruva Kumar Goyal

Qualification: M.Tech.

Affiliation: Department of Mechanical Engineering, Indian Institute of Technology Ropar,

Contact details: Email ID: 2018MEZ0007@iitrpr.ac.in, Phone Number: +91-6280269238

ORCID: https://orcid.org/0000-0003-2904-6419

Mr. Ramsingh Yadav

Qualification: M.Tech.

Affiliation: Department of Mechanical Engineering, Indian Institute of Technology Ropar, Contact details: Email ID: 2018mez0006@iitrpr.ac.in, Phone Number: +91-9414851117

ORCID: https://orcid.org/0000-0003-1974-8759

Dr. Ravi Kant

Qualification: Ph.D.

Affiliation: Department of Mechanical Engineering, Indian Institute of Technology Ropar, Contact details: Email ID: ravi.kant@iitrpr.ac.in; only4ravikant@gmail.com, Phone Number: +918275256587

ORCID: https://orcid.org/0000-0001-5414-4139

\section{Acknowledgments}

The laser system used for this study was established through grant received from Department of Science and Technology (DST), India under project number DST/TDT/AMT/2017/026.

\section{Declarations}

Funding: Authors did not receive any funding for this research work.

Conflicts of interest/Competing interests: Authors declare that there is no conflict of interest.

Availability of data and material: Authors confirm that the data and material supporting the findings of this study are available within the article. Raw data are available from the corresponding author upon reasonable request.

Code availability: DFLUX subroutine is written in Fortran to incorporate the moving heat flux. The subroutine code can be provided by corresponding author upon reasonable request.

Authors' contributions:

Dhruva Kumar Goyal has proposed the methodology and performed the numerical simulations and experiments, including data analysis, and drafted the original manuscript.

Ramsingh Yadav coordinated and helped in the development of experimental setup, conducting the experiments, and editing the original manuscript.

Ravi Kant has supervised the overall project from conceptualization to methodology. He has reviewed and edited the primary manuscript. He also led the project and overall collaborative effort of all entities. 


\title{
An integrated hybrid methodology for estimation of absorptivity and interface temperature in laser transmission welding
}

\begin{abstract}
:
This study reports a new hybrid integrated technique to predict the absorptivity of absorber and the interface temperature of the joint in laser transmission welding. The new approach is more robust as the numerical model is confirmed through experimental observations initially with weld width and further with surface temperature. Experiments are performed on a polycarbonate sheets with electrolytic iron powder (EIP) as an absorber. The surface temperature and weld width are measured from the experiments. A transient 3-D finite elementbased numerical model is developed for heat transfer analysis. The variation of heat flux with stand-off distance is also considered to enhance the accuracy of the computed results. The absorptivity is tuned in the numerical model so that the numerical weld width is in close conjunction with the experimental weld width. The numerical model is validated by comparing the upper surface temperatures at the center, measured in the experiments using infrared thermography. The results indicate that the surface temperatures in the numerical model are in good agreement with experimental observations, and the average error is less than $6 \%$. The interface temperatures are estimated after the validation of the numerical model.
\end{abstract}

Keywords: Laser transmission welding (LTW); Electrolytic iron powder (EIP); Absorptivity; Finite element model; Interface temperature; Inverse estimation. 


\section{Introduction}

Laser transmission welding (LTW) is an innovative method to join polymers as it has several advantages over its contemporary joining methods(Liu et al., 2018). It is a fast, non-contact, non-contaminated joining process with high flexibility, automation, easy to control, consistent quality, and product stability. In addition, this process can produce a high-quality joint with low thermal and mechanical stresses with a narrow seam geometry(Pereira et al., 2019). These qualities of LTW make it possible to broaden its applications in the field of automobile components, electronic and medical devices, and food-packaging industries(Acherjee, 2021b).

A defocused laser beam passes through the upper substrate, which is transparent to the laser wavelength. When the laser beam reaches the interface, it is absorbed by the absorber and transformed into heat. Clamping pressure is critically required for the proper contact of surfaces as the heat at the interface can melt the polymers by thermal conduction. The combined effect of pressure and temperature results in the diffusion of polymeric chains, and joining of the polymer sheets occurs after solidification. Therefore, measuring the temperature at the interface is critical to verify the melt pool. The temperature should be enough to ensure the joining of the substrates but not be too high; otherwise, degradation near the interface of the workpiece can occur(Villar et al., 2018).

In LTW, a lap-joint configuration is widely used. However, temperature field investigation at the interface is difficult to monitor in lap joint configuration. Measuring interface temperature using thermocouples is also unsuitable because of the variation in thermal conductivity and absorptivity of thermocouple wires(Becker \& Potente, 2002). Pyrometer is an inexpensive, simple, and non-contact type method to measure the temperature at the interface; however, the heat emitted at the joining zone should be high enough, which must be susceptible to different wavelengths (Horn, 2009). Infrared (IR) thermography is a real-time thermal monitoring method used in laser transmission welding. IR thermography measures the temperature field distribution at the surface of the object by emitting the radiation at the time of welding(Ilie et al., 2007). Due to the optical envelop at the interface, it cannot provide thermal information of the joining zone. Therefore, the researchers have developed numerical models to investigate the interface temperature in the LTW process (Speka et al., 2008).

Becker \& Potente (2002) established a model to analyze the melt profile in the heating phase of LTW in the contour welding of polypropylene. Ven \& Erdman (2007) developed a 2-D heat transfer model for thermal analysis in LTW of PVC. Mahmood et al. (2007) developed an FEA- 
based analysis to get the temperature distribution at different process parameters by comparing it with weld width obtained experimentally. Mayboudi et al. (2015) developed a 3-D FE-based thermal model to investigate the heating and cooling stages in LTW by a moving laser beam source and overcome some assumptions made in previous models. Acherjee et al. (2012) developed a 3-D FEM model to investigate the effect of carbon black content in weld profile with temperature-dependent thermal properties. Sooriyapiragasam \& Hopmann (2016) developed a thermo-mechanical simulation model for spatial temperature and stress distribution in weld seam. Liu et al. (2018) created a finite element model to analyze the role of thermal conductivity of metal absorber in the weld seam and temperature distribution. Wang et al. (2021) developed a finite element-based model to investigate the effect of thermal contact conductance. The temperature distribution and the weld width were found in excellent agreement with experimental results. Acherjee (2021) developed a 3-D FE-based model for LTW of dissimilar plastics. The dilution effect at the weld pool was considered in simulation and found that it affected the maximum temperature zone.

Literature reports a number of numerical models which consider the tuned absorptivity. Most of these models are not validated with the experimental temperature field. These models may be not be able to predict the process outcomes accurately for a wide range of parameters. Incorporation of effective absorptivity and validation of the model with actual temperature field can make the model reliable and accurate for a wide range of process conditions. In this paper, a hybrid integrated approach which is based on experiments, numerical analysis, and inverse estimation approach has been developed to estimate the absorptivity and interface temperature for lap-joint configuration in LTW. For this purpose, experiments are carried out at different process parameters, i.e., laser power and scanning speed. In experiments, the temperature has been measured by the infrared camera and weld width by tool maker microscope. A 3-D finite element model is developed to validate the results and estimate the temperature at the interface.

\section{Materials and methods}

\subsection{Methodology}

The experiments of LTW are conducted to join PC workpiece with electrolytic iron powder (EIP) at different process parameters. The flow chart of the procedure to find the interface temperature is shown in Fig.1. In-process thermal field distribution over the top surface of PC is measured through infrared (IR) thermography. Weld width of the workpiece joint is measured by a tool maker microscope. A three-dimensional finite element model is developed 
for transient thermal analysis. Weld width in the numerical model is compared with the experimental weld width. Numerical weld width is a function of temperature-dependent thermal properties of PC, applied boundary conditions, and absorption of the irradiated laser beam at the interface. The numerical model consists of temperature-dependent material properties, and boundary conditions are applied as per the real-time condition of the workpiece. The only parameter which is unknown and can affect the weld width significantly is the absorptivity. Therefore, weld width in simulations is adjusted by tuning absorptivity using the bisection method in such a way that the difference between experimental and numerical values are less than $0.1 \mathrm{~mm}$. After this, validation of the numerical model is done by comparing the top surface temperature obtained from the numerical model with the experimental temperature by IR camera. The validated model is then used to estimate maximum temperatures at the workpiece interface. 


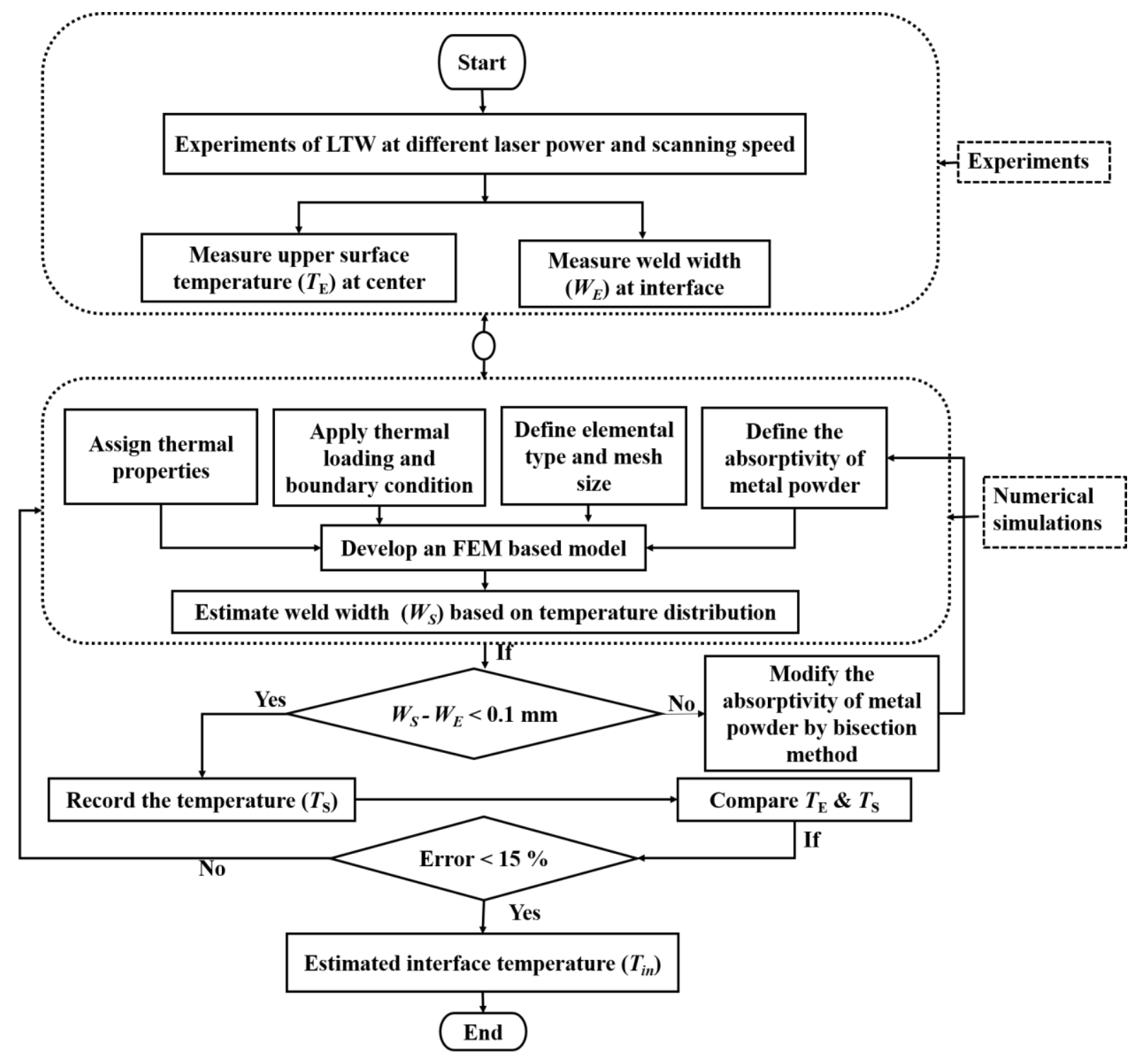

Fig. 1 Flow chart represents the development and calibration of interface temperature in laser transmission welding.

\subsection{Experiments}

The experiments are performed on a polycarbonate sheet $(70 \mathrm{~mm}$ x $30 \mathrm{~mm}$ x $2 \mathrm{~mm}) . \mathrm{CO}_{2}$ laser cutting machine (ELITA 480, MEHTA CAD-CAM, INDIA) was used for sample cutting. Polycarbonate specimens are cleaned by using ethyl alcohol of purity $90 \%$ to remove dust, foreign particles, and decoloration effect during the cutting of specimen by $\mathrm{CO}_{2}$ laser. The transmittance and absorbance of the polycarbonate with respect to air are measured using Ultra Violet Visual Near-Infrared Spectroscopy (UV-VIS-NIR, UV-2700 SHIMADZU, JAPAN), in the range of $800 \mathrm{~nm}-1400 \mathrm{~nm}$. These are required for numerical simulations to determine the temperature in the joining zone. The results of transmittance (T\%), and absorbance (A\%) of 
polycarbonate are shown in Fig. 2. The reflectance $(\mathrm{R} \%)$ of the polycarbonate substrate can be calculated from equation (1)

$$
R=1-T-A
$$

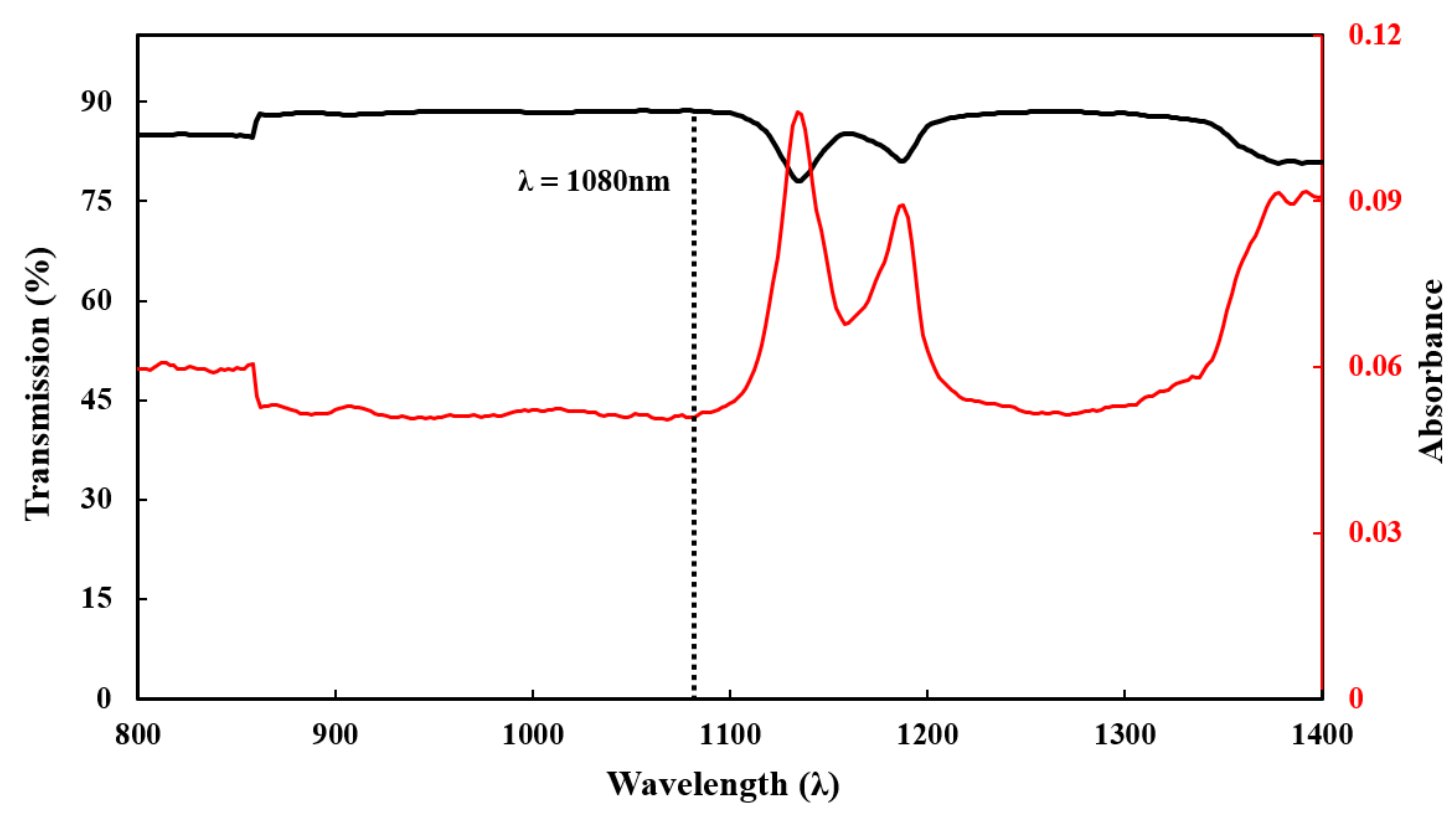

Fig. 2 Transmittance (\%) and absorbance of polycarbonate at $800-1400 \mathrm{~nm}$ wavelengths measured by UV-VIS-NIR.

EIP is used as an absorber which is spread along the travel length of the laser beam and smeared uniformly with the help of a blade. There are two reasons behind smeared EIP particles at the interface. The first is to obtain a semi-transparent joining interface, and the second is to absorb radiation at the interface only.

The experiments on transmission welding are performed using a $1000 \mathrm{~W}$ Fibre laser source (MAX -MFSC-1000W, CW) system with a wavelength of $1080 \mathrm{~nm}$. The laser head is mounted on a computer-controlled 3- axis CNC system for the precise speed and position of the laser beam. At 1080nm wavelength, the PC sheet is found to transmit $89 \%$ and reflect $5 \%$ of the total incident laser beam energy, as shown in Fig. 2. A stand-off distance of $63 \mathrm{~mm}$ and the beam spot diameter of $6 \mathrm{~mm}$ are used in the following experiments. The PC workpieces are placed in a lap joint configuration between four plates of mild steel of $60 \mathrm{~mm}$ x $15 \mathrm{~mm}$ x 15 $\mathrm{mm}$, as shown in Fig. 3. Pressure is applied for proper contact between PC substrate and iron powder so that heat can transfer through conduction. The laser beam irradiation is started and stopped at $10 \mathrm{~mm}$ away from the sheet so that the effect acceleration and deacceleration of the moving parts can be avoided. 


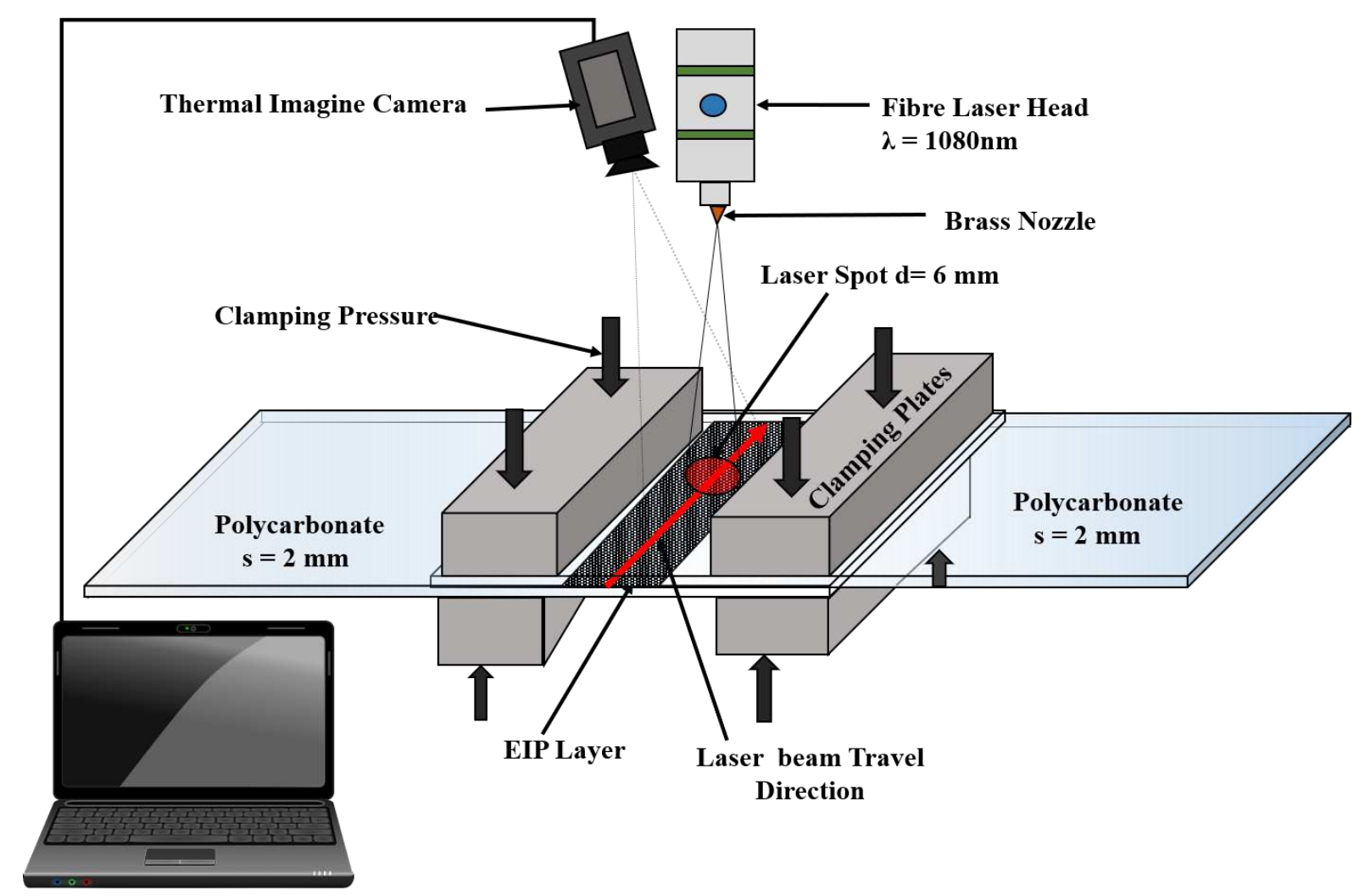

Monitoring System

Fig. 3 Experimental setup for LTW of polycarbonate sheet.

The surface temperature is measured by IR camera (A315, FLIR, SWEDEN) at the time of experiments. This IR camera is equipped with a lens of $18 \mathrm{~mm}$ focal length and characterized for the spectral range $7.5-13 \mu \mathrm{m}$. The IR camera is placed at $0.5 \mathrm{~m}$ distance from the sheets at an angle of approximately $45^{\circ}$. The frame rate to capture the temperature of the upper surface of polycarbonate is taken as $60 \mathrm{~Hz}$. The temperature range is set at $0-500{ }^{\circ} \mathrm{C}$ because PC starts to degrade above this temperature.

A tool maker microscope (RTM-900, RADICAL, INDIA) with a magnification of $15 \mathrm{x}$ is used to investigate the weld width and internal morphology of the joint at different process parameters. Weld width is measured at the three different points along the weld length, and an average of these weld widths has been taken. A full factorial $4 \times 3$ design of the experiment at different levels is listed in Table 1.

Table 1 Experimental plan: Process parameters and their levels.

\begin{tabular}{ccccc}
\hline Parameters & Level 1 & Level 2 & Level 3 & Level 4 \\
\hline Laser power $(\mathbf{W})$ & 80 & 100 & 120 & 150 \\
\hline $\begin{array}{c}\text { Scanning speed } \\
(\mathbf{m m} / \mathbf{m i n})\end{array}$ & 200 & 400 & 600 & \\
\hline
\end{tabular}




\subsection{Numerical modeling of LTW}

Thermal analysis of laser transmission welding of polycarbonate is carried out by finite element analysis using ABAQUS software. The geometry and dimensions of substrates are shown in Fig. 4. The temperature-dependent thermal properties are shown in Table 2. Due to symmetry in geometry and material properties, half of the model is considered for the current analysis to reduce the simulation time. The interaction time of the laser beam at the interface is very less, and heating in a narrow region also favors the above consideration. The following assumptions are considered in the development of the FEM model:

1. Material is considered to be homogeneous and isotropic

2. The laser beam is assumed circular and follows the Gaussian distribution of intensity

3. There is perfect contact between the substrates

4. Iron powder is considered a flat layer at the upper surface of the nether PC only to absorb the laser energy

5. The thermal contact conductance is assumed to be very high 


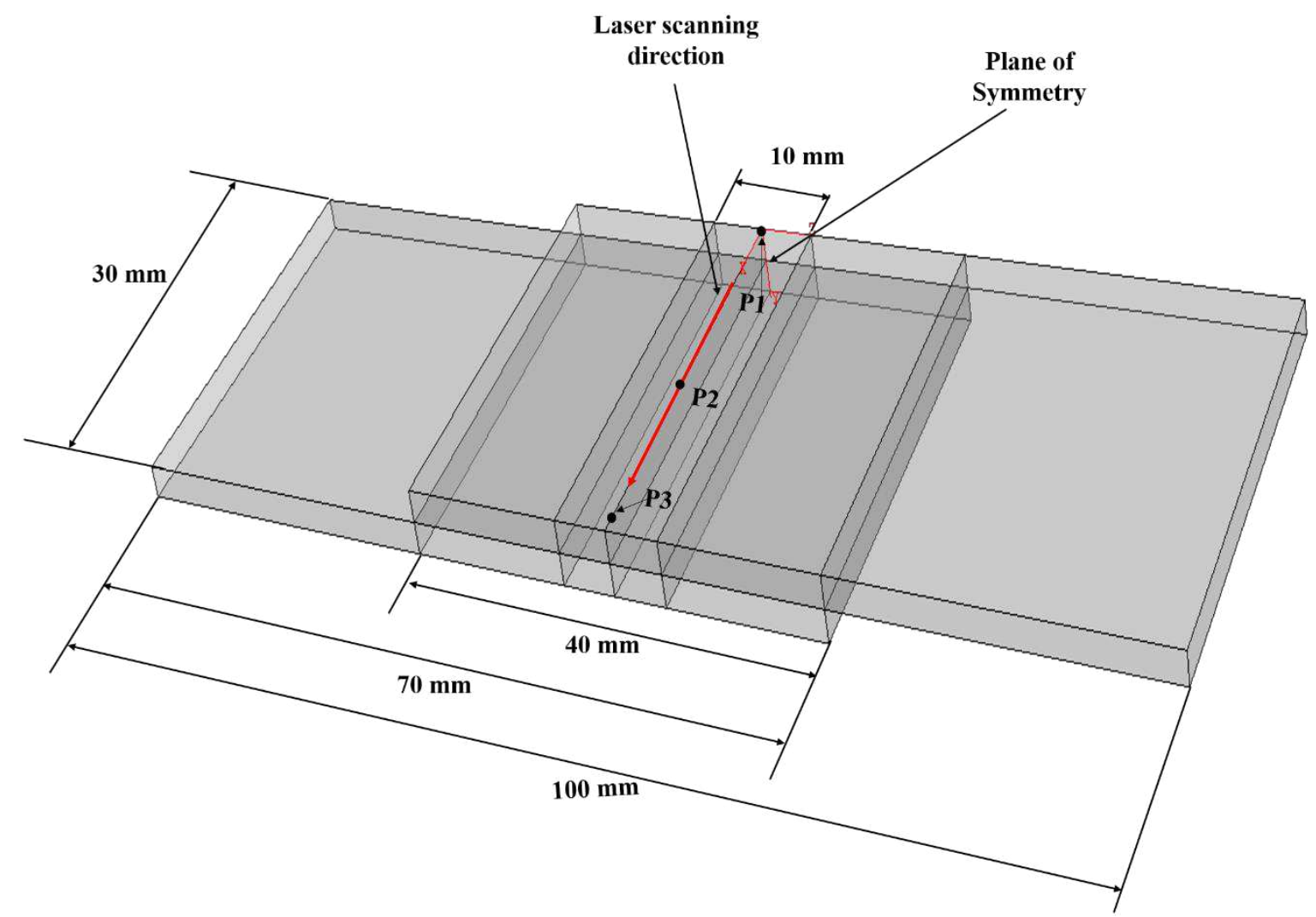

Fig. 4 Schematic view of dimensions, boundary conditions and beam direction used in lap joint.

Table 2 Temperature-dependent thermal properties of polycarbonate used in numerical modelling (Wang et al., 2021).

\begin{tabular}{|c|c|c|}
\hline Properties & value & Condition \\
\hline \multirow[t]{2}{*}{ Density $(\rho)\left(\mathrm{kg} / \mathrm{m}^{3}\right)$} & $-0.319 T+120$ & $27 \leqslant T \leqslant 145^{\circ} \mathrm{C}$ \\
\hline & $-0.685 T+1253$ & $T>145^{\circ} \mathrm{C}$ \\
\hline \multirow[t]{2}{*}{ Thermal conductivity $(k)(W / m-K)$} & $k=(2.493 \mathrm{E}-4) T+0.186$ & $27 \leqslant T \leqslant 145^{\circ} \mathrm{C}$ \\
\hline & $-(5.536 \mathrm{E}-5) T+0.23$ & $T>145^{\circ} \mathrm{C}$ \\
\hline \multirow[t]{3}{*}{ Specific heat capacity $(c)(\mathrm{J} / \mathrm{Kg}-\mathrm{K})$} & $c=3.42 T+1120.67$ & $27 \leqslant T \leqslant 140^{\circ} \mathrm{C}$ \\
\hline & $27.385 T-2236.38$ & $140 \leqslant T \leqslant 147^{\circ} \mathrm{C}$ \\
\hline & $1.771 T+1537.41$ & $T>147^{\circ} \mathrm{C}$ \\
\hline Glass transition temperature $\left(T_{\mathrm{g}}\right)\left({ }^{\circ} \mathbf{C}\right)$ & $145-150{ }^{\circ} \mathrm{C}$ & \\
\hline Flow temperature $\left(\boldsymbol{T}_{\mathrm{f}}\right)\left({ }^{\circ} \mathbf{C}\right)$ & $230-240^{\circ} \mathrm{C}$ & \\
\hline decomposition temperature, $\left(T_{\mathrm{d}}\right)\left({ }^{\circ} \mathrm{C}\right)$ & $550^{\circ} \mathrm{C}$ & \\
\hline
\end{tabular}

\subsubsection{Laser beam model}

A continuous-wave laser heat source is moving with uniform velocity $(V)$ along the weld line. The laser beam has a Gaussian heat flux distribution inside the beam diameter. The PC sheet is transmitted $90 \%$, absorbed $5 \%$ of the total radiation, and the rest is reflected. The PC sheet 
absorbs the radiation along with the thickness(s); therefore, volumetric heat flux is applied in the model for laser beam interaction with PC along the weld line. The volumetric heat flux $\left(Q_{v}\right)$ described by Equation 2 as:

$$
Q_{v}=\frac{\alpha_{v} P}{\pi R^{2} s} \exp \left(-\frac{2\left((x-V * t)^{2}+z^{2}\right)}{R^{2}}\right),
$$

where $P$ is the peak laser power, $x$ and $z$ are the coordinates of the laser beam along the weld length and width respectively, and $t$ is the time. The volumetric absorptivity coefficient, $\alpha_{v}$ is taken as 0.05 and $R$ is beam spot radius.

The laser beam is transmitted through the PC sheet and irradiates iron particles. The heat flux is absorbed by these particles, termed as surface heat flux $\left(Q_{s}\right)$, represented by Equation 3 as:

$$
Q_{S}=\frac{\alpha_{s} \tau P}{\pi R^{2}} \exp \left(-\frac{2\left((x-V * t)^{2}+z^{2}\right)}{R^{2}}\right)
$$

where, $\alpha_{s}$ is the effective absorptivity of iron powder, and $\tau$ is the transmissivity which incident on the iron powder which is taken as 0.9, obtained from the results of Fig. 2. Laser beam spot can be controlled by adjusting the distance from the focal point (set at the nozzle tip) to the workpiece surface. The spot radius of the laser beam at the stand-off distance $H$ from the focal point can be described by the mathematical model(Kant \& Joshi, 2016) as shown below:

$$
R=w_{o} \sqrt{1+\left(\frac{M^{2} \lambda(H+y)}{\pi w_{o}^{2}}\right)}
$$

where, $w_{o}=10 \mu \mathrm{m}$ is the beam waist radius at the focal point, $\lambda$ is the wavelength of the laser beam and $y$ is the depth of the workpiece. $M^{2}$ is the beam quality factor. For a perfect Gaussian beam, the value of the beam quality factor is taken 1. But, in this analysis beam quality factor is calculated analytically by Equation 5 as shown below:

$$
M^{2}=\frac{\pi w_{o} \theta_{d}}{\lambda},
$$

where, $\theta_{d}$ is the half divergence angle which can be calculated by:

$$
\theta_{d}=\frac{R_{0}}{f}
$$

where, $f$ is the focal length of the lens used to focussing the laser beam, equal to $125 \mathrm{~mm}$ and $R_{0}$ is the radius of the laser beam before the lens. By putting equation (6) in equation (5), we can get the value of $M^{2}=1.39$ 


\subsubsection{Heat Flow model}

The laser energy is absorbed and generates heat at the interface. The heat is transferred between the substrates mainly through thermal conduction. The spatial and temporal temperature field is determined by a 3-D heat conduction equation. It is based on the energy conservation law, which balances the rate of heat generated internally in the body, the capacity of the body to store the heat, and the rate of heat conduction to the boundaries.

$$
\nabla \cdot(k \nabla T)+Q(x, y, z, t)=\rho c \frac{\partial T(x, y, z, t)}{\partial t},
$$

where $\nabla$ is the gradient operator, $k$ is the thermal conductivity, $T$ is the temperature, $Q$ is the heat generated per unit volume, $x, y, z$ are the cartesian coordinates and $\rho$ is the density.

Heat loss from the surface exposed to the surroundings is primly due to natural convection. The boundary condition for heat transfer by convection is defined by equation

$$
q_{\text {conv }}=h\left(T_{n}-T_{o}\right)
$$

where, $h$ is the heat transfer coefficient. $T_{n}$, is the node temperature and $T_{o}$, is the surrounding temperature taken as $33{ }^{\circ} \mathrm{C}$. The radiation heat loss is neglected concerning conduction and convection.

\subsubsection{Model Description}

A 3-D FEM-based heat transfer model is developed for the analysis of temperature in the weld zone by using an ABAQUS/ standard solver. An 8-node linear heat transfer brick element DC3D8 is used for the analysis. The region prone to a significant portion of laser power is discretized into a finer mesh region of element size $0.25 \times 0.25 \times 0.25 \mathrm{~mm}$. The region away from the heated region is discretized in biased coarser mesh to reduce the computational time, as shown in Fig. 5. 


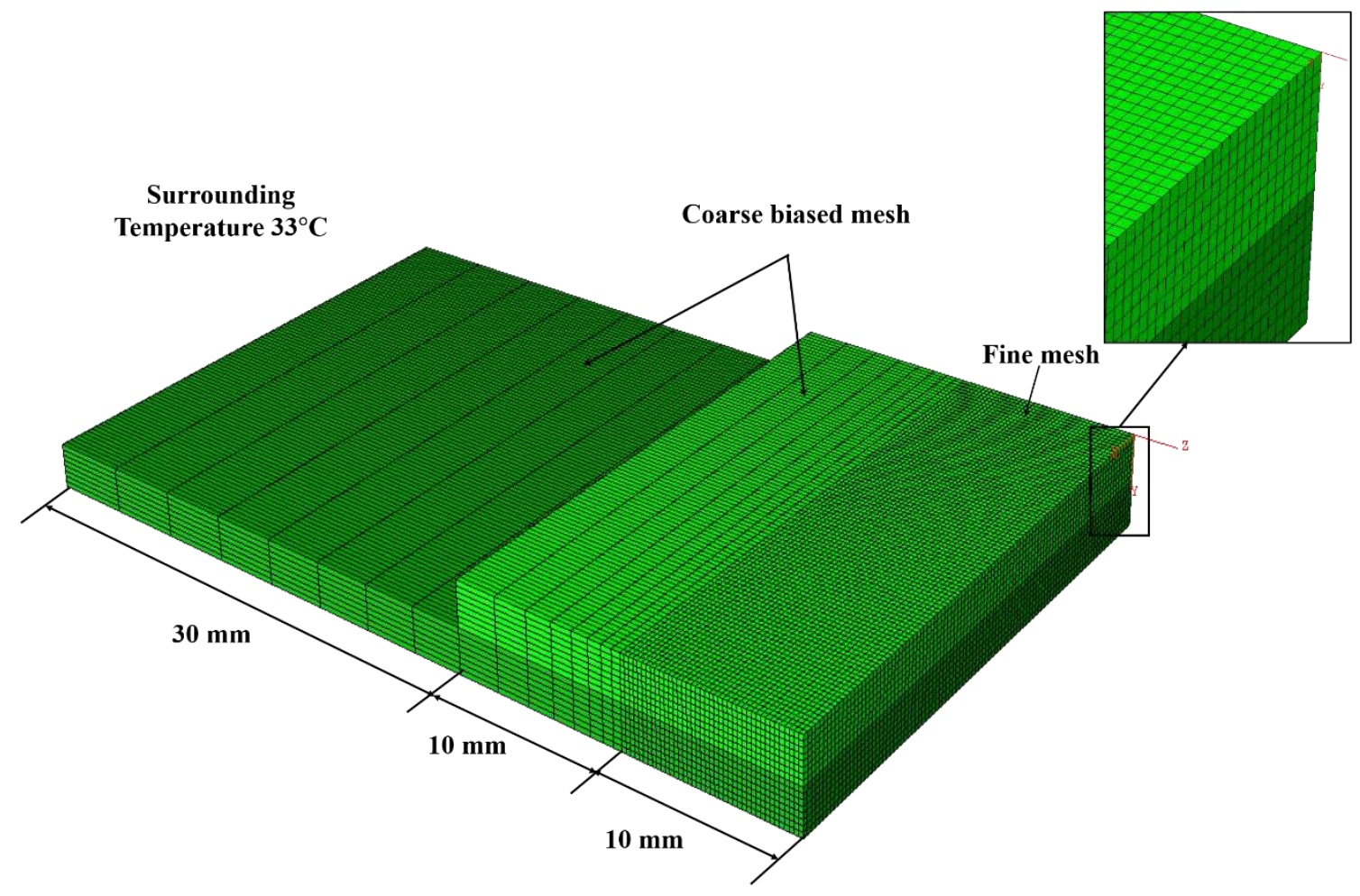

Fig. 5 Meshed part used in numerical simulation.

The moving body heat flux at the upper PC and surface heat flux at the nether PC is applied through a user-defined dflux subroutine. A single, self-adaptive time step is used to perform the thermal analysis. In this step, initial time is given for the heating phase and later for cooling of the substrate. The maximum and minimum time steps were taken as $2 \mathrm{~s}$ and $5 \times 10^{-5} \mathrm{~s}$, respectively. Maximum allowable temperature change per increment is taken as $30^{\circ} \mathrm{C}$.

\section{Results and discussions}

\subsection{Calibration of emissivity}

A fine emissivity of polycarbonate surface is essential for the quantitative measurement of temperature by infrared thermography. For this purpose, the polycarbonate sheet is heated by placing it on a hot plate. In addition, a K-type thermocouple is attached to the top surface of the PC sheet, connected with a data acquisition (DAQ) system to get a real-time temperature. The infrared camera is focussed at a point ( $\mathrm{Sp} 1)$ on the surface of the polycarbonate by choosing the arbitrary emissivity to show the room temperature, as shown in Fig. 6. (a). The plate is heated in a step of $20^{\circ} \mathrm{C}$ from room temperature to $150{ }^{\circ} \mathrm{C}$. 


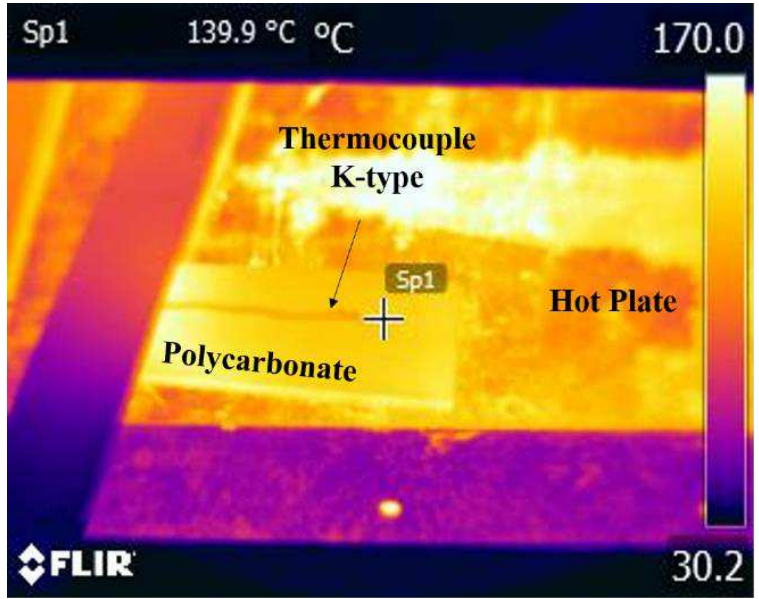

(a)

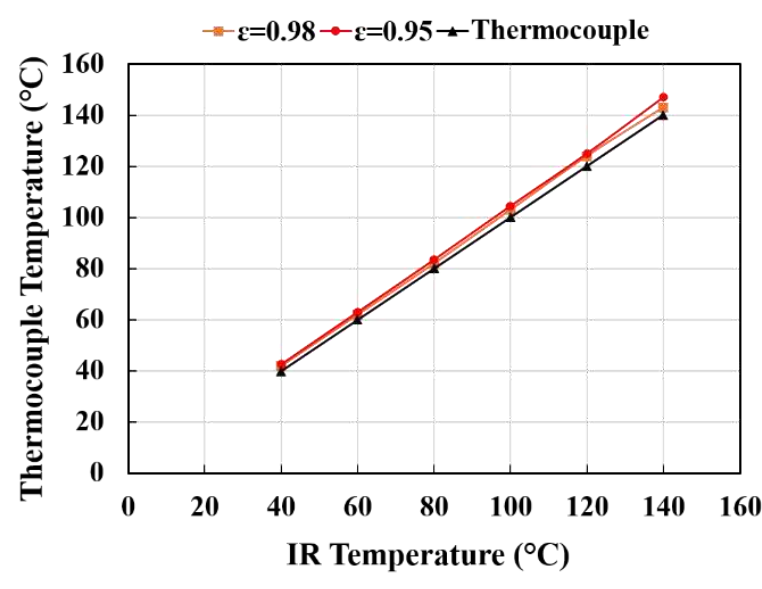

(b)

Fig. 6 Calibration of emissivity of polycarbonate surface (a) Infrared measurement (b) comparison of thermocouple and infrared temperature at different emissivity.

The temperature is recorded in the DAQ system when it reaches at a steady-state condition. Thermocouple temperature is compared with the infrared measured value at different emissivity to get a close temperature value as measured by a thermocouple. It is observed that surface temperature is in good agreement with an average error $<2 \%$ for the infrared emissivity at 0.98 , up to $140{ }^{\circ} \mathrm{C}$ as sown in Fig. 6. (b). The hot plate is not heated above $150{ }^{\circ} \mathrm{C}$ as above this temperature workpiece started to lose its shape.

\subsection{Calibration of absorptivity of iron powder}

It is important to provide a calibrated properties to a finite element-based model to predict the temperature of the interface at the joining zone. The absorptivity is such an important parameter that directly affects the heat generated by the absorber. The absorptivity of a substance depends on the laser wavelength and the process conditions, concentration, temperature, shape, and size of the absorber. Laser beam falls on the iron particles, a part of the laser beam is absorbed by the iron powder particles and transmitted through the micropores, remaining after the coating, and the rest is reflected. Therefore, an inverse analysis has been done for measuring the effective absorptivity at different process conditions. For each process condition, the experimental weld width $\left(W_{E}\right)$ is measured and compared with simulation weld width $\left(W_{S}\right)$ by adjusting absorptivity so that the difference in their values lies less than $0.1 \mathrm{~mm}$. The results of absorptivity at different process conditions are shown in Fig.7. 


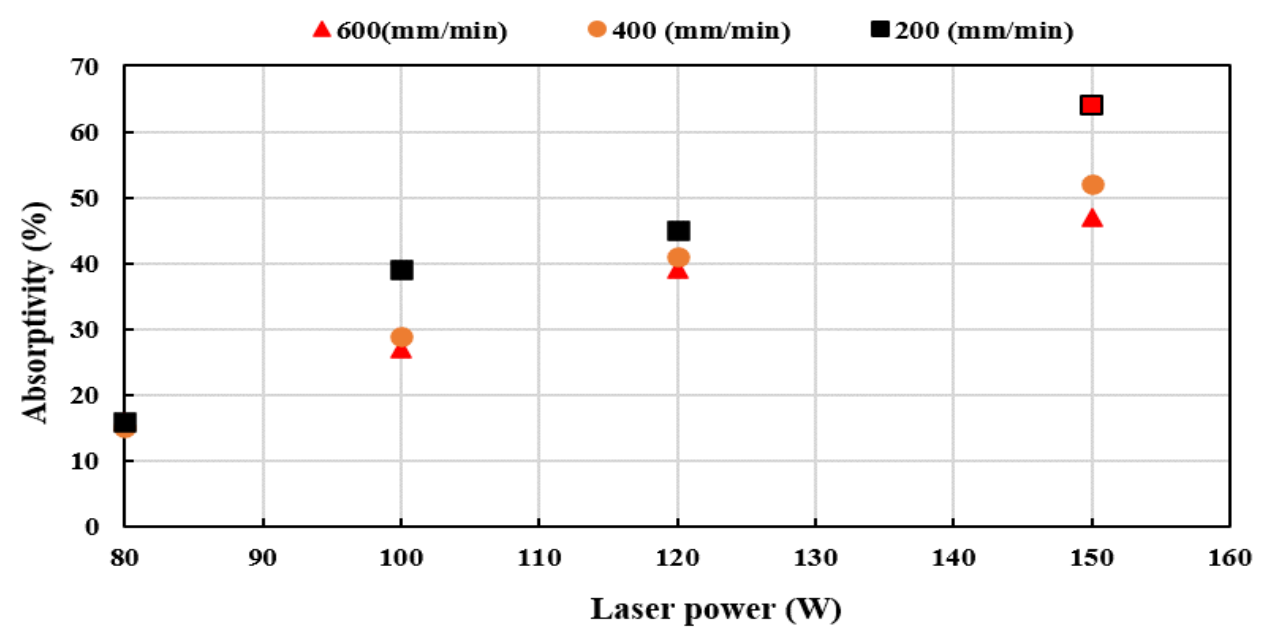

Fig. 7 Variation of absorptivity with laser power at different scanning speeds.

The absorptivity increases with increasing the laser power and decreasing the scanning speed. It may happen because as the laser beam irradiates, the temperature at the interface increases, which melts the PC at the interface. The rise in interface temperature softens the iron powder particles, which increases the absorptivity. The absorptivity is almost constant with scanning speed at low laser power $(80 \mathrm{~W})$, as the generated temperature is less than the melting temperature of PC. Furthermore, at high scanning speed, the laser beam is irradiated for a shorter time, which reduces the diffusion of laser beam energy into the iron particles and decreases the absorptivity.

\subsection{Weld width}

The effect of laser power on weld width at different scanning speeds is shown in Fig. 8(a). At all scanning speeds, the weld width increases with laser power due to more heat absorption at the interface. The weld width, measured by tool maker microscope at $\mathrm{P}=80 \mathrm{~W}$ and $\mathrm{V}=200$ $\mathrm{mm} / \mathrm{min}$, is shown in Fig. 8(b). One exception case of decreasing weld width is found at a low scanning speed of $200 \mathrm{~mm} / \mathrm{sec}$ and high power of $150 \mathrm{~W}$. At these parameters, the laser beam is absorbed by the upper surface of the PC and started the degradation or burning of the workpiece. The average weld width is decreased with increasing the scanning speed. This is due to the fact that by increasing the scanning effect, the time of laser beam interaction with the EIP is decreased, which reduces the amount of heat generated at the interface. The difference in weld width is more at different scanning speeds at low power compared to high laser power. This is due to the fact that at low laser power, more non-uniform welding is obtained along the scan line. 


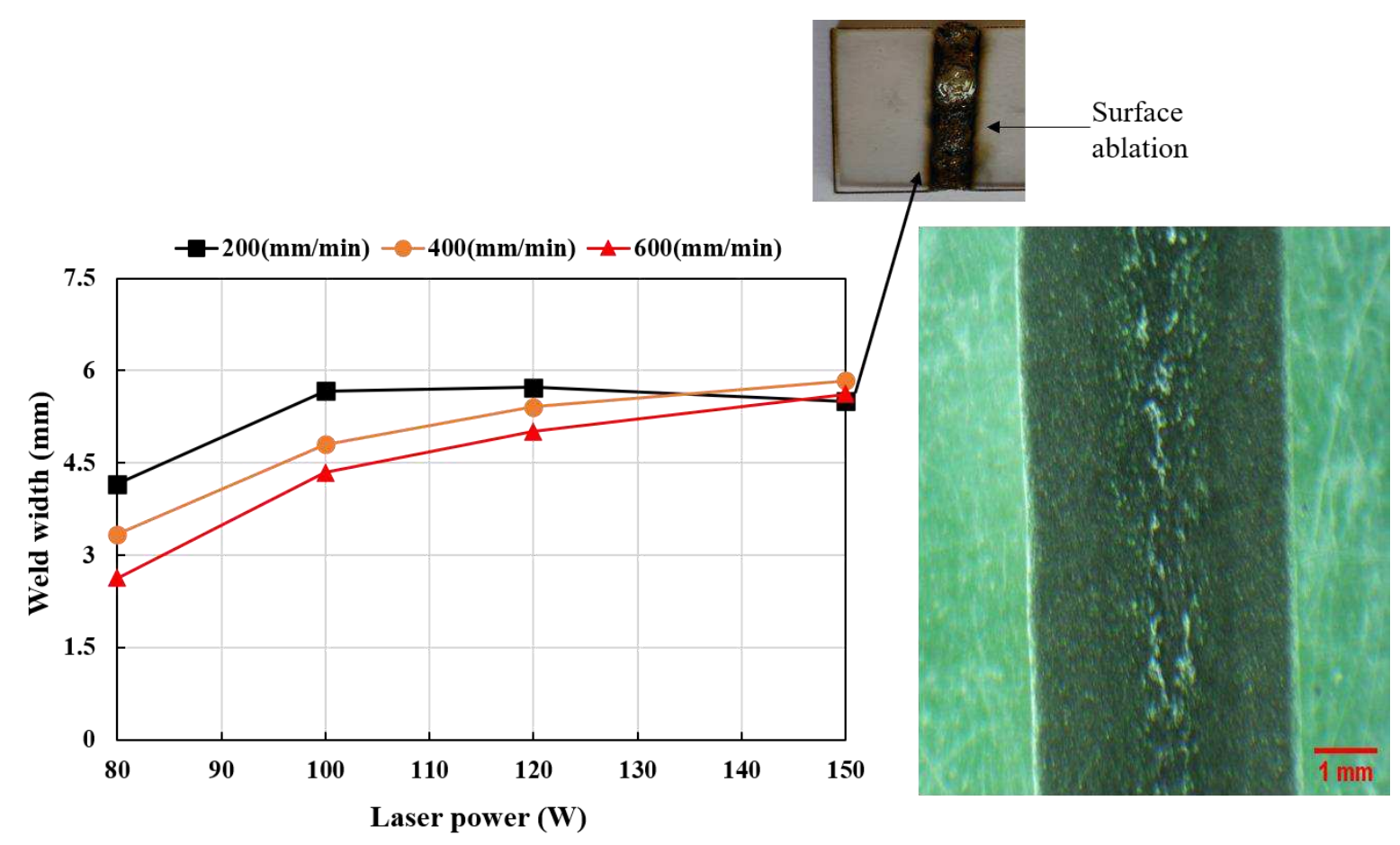

(a)

(b)

Fig. 8 Variation of weld width with laser power at different scanning speeds (b) weld width measured in the tool maker microscope for $P=80 \mathrm{~W}$ and $V=200 \mathrm{~mm} / \mathrm{min}$.

At the time of measurement of weld width, it is assumed that the joining process started when the temperature at interface reached $160{ }^{\circ} \mathrm{C}$, above the glass transition temperature of PC $\left(\mathrm{T}_{\mathrm{g}}=150{ }^{\circ} \mathrm{C}\right)$. The weld width measured experimentally and by numerical simulation is compared as shown in Fig. 9. As the minimum width of the element is $0.25 \mathrm{~mm}$, and the maximum error is restricted below $0.1 \mathrm{~mm}$, an image processing software has been used to achieve high accuracy. This is seen that the maximum weld width, $\mathrm{W}_{\mathrm{E}}$, is lower than the beam diameter $(\mathrm{d}=6 \mathrm{~mm})$ of the laser beam. 


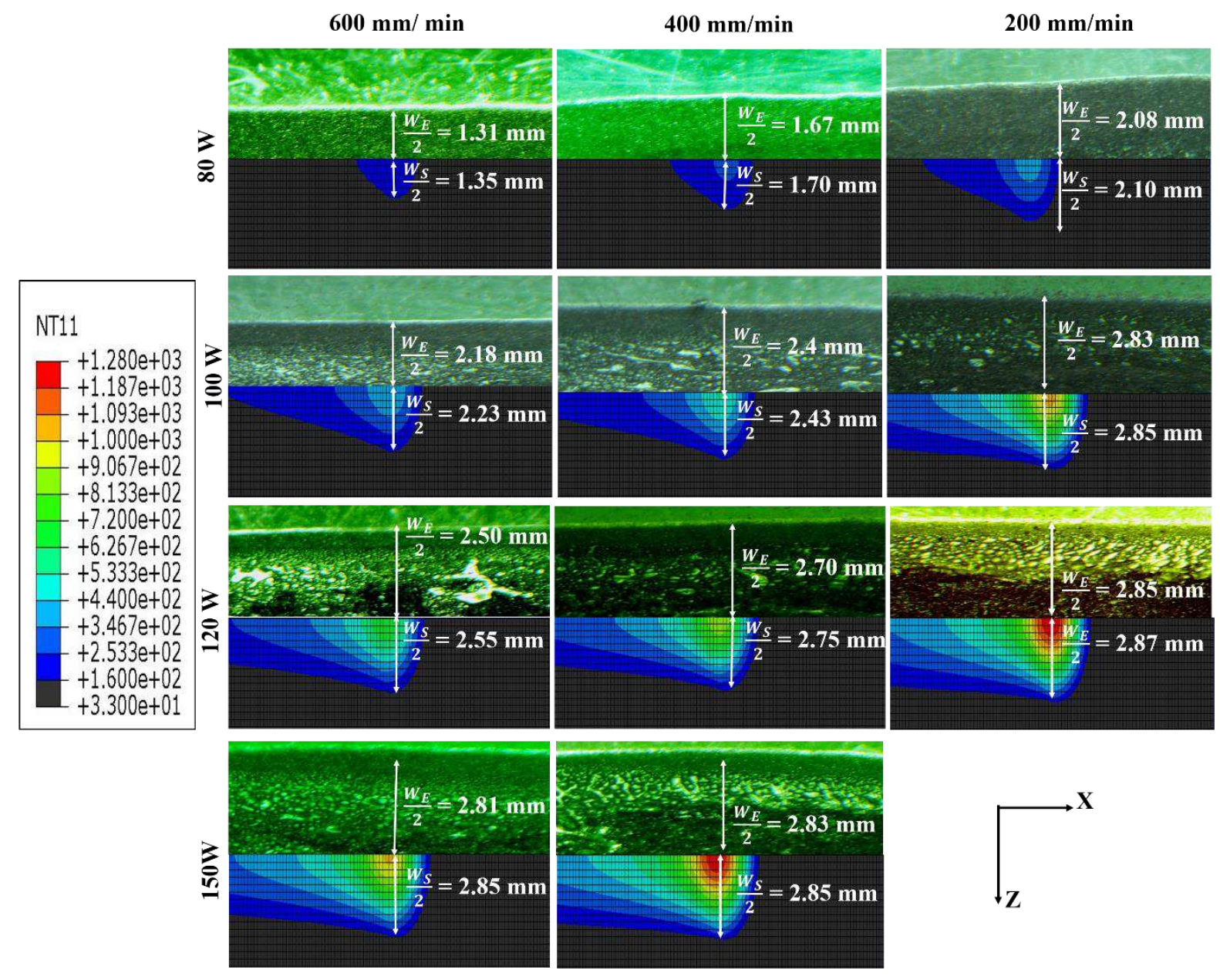

Fig. 9 Comparison of experimental weld width measured with a tool maker microscope and simulated weld width measured with temperature profile.

\subsection{Temperature Analysis}

Since PC is opaque in the IR range, therefore it provides the temperature reading of the upper surface of PC. The temperature distribution along the weld length at different time interval for $P=100 \mathrm{~W}$ and $V=600 \mathrm{~mm} / \mathrm{min}$ is shown in Fig. 10. It shows the initial contact of the laser beam to PC at $t=1 \mathrm{~s}$ in Fig. 10(a), laser beam reaches at the middle of weld length at $t=2.5 \mathrm{~s}$ in Fig. 10(b), at the endpoint of interaction $t=4 \mathrm{~s}$ in Fig. 10(c) and at $t=9 \mathrm{~s}$ in Fig. 10(d), after $5 \mathrm{~s}$ of passing the laser beam from the endpoint. The measured values of temperature with time at different positions is represented in Fig. 11. It is observed that the high temperature at the top surface of PC is reached after some time of laser irradiation. It is due to the fact that the laser is absorbed at the joining interface for a very short time on the iron powder and the PC has very less thermal conductivity. For better understanding, this temperature distribution can be divided into three regions. In the first irradiated region, O-A, a very small initial temperature rise occurs and is maintained constant till the time of interaction. Thereafter, it comes into the 
conduction zone, A-B, where the temperature increases continuously to a maximum and then decreases in the cooling phase in B-C.
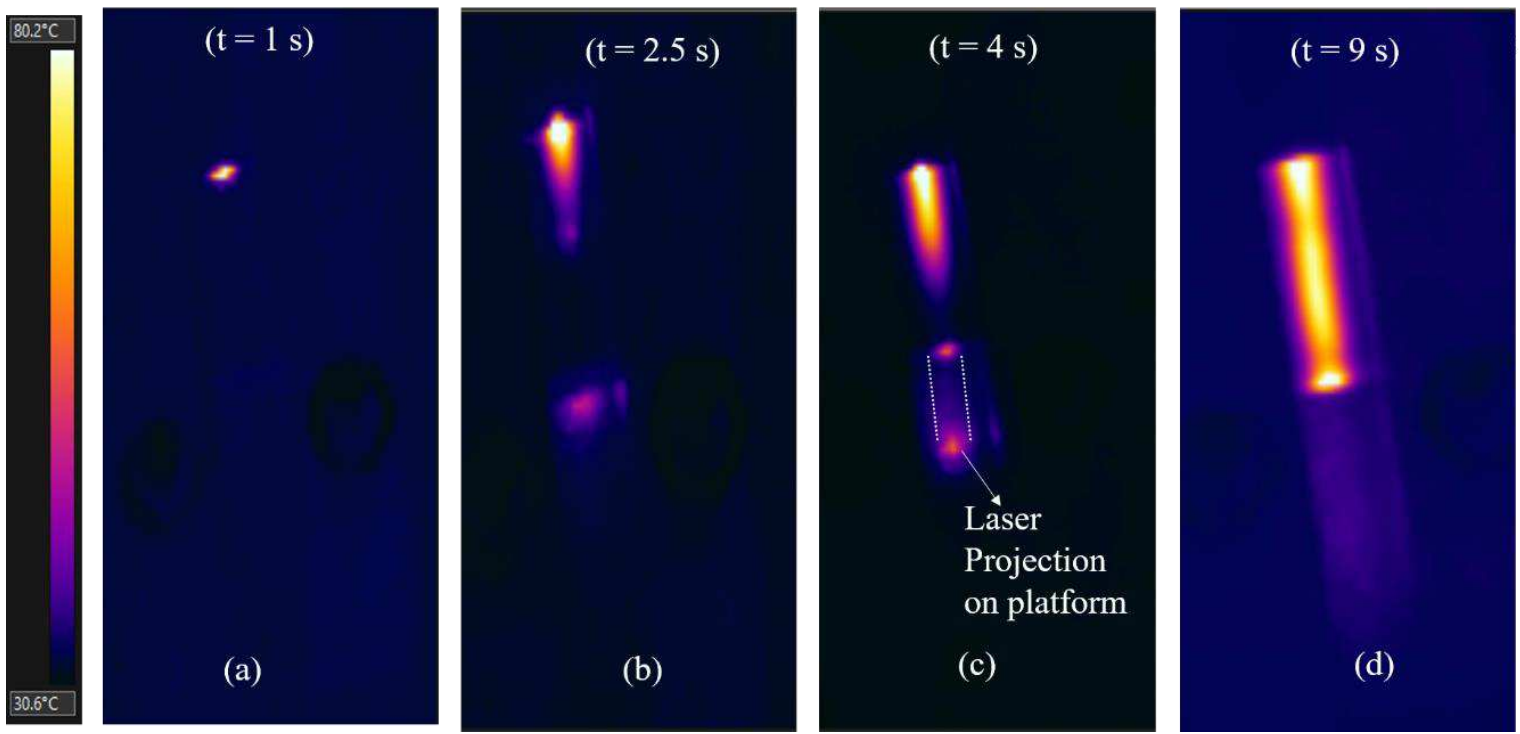

Fig. 10 IR measurement of top surface temperature of $P C$ at different time intervals for $P=$ $100 \mathrm{~W}$ and $V=600 \mathrm{~mm} / \mathrm{min}$.

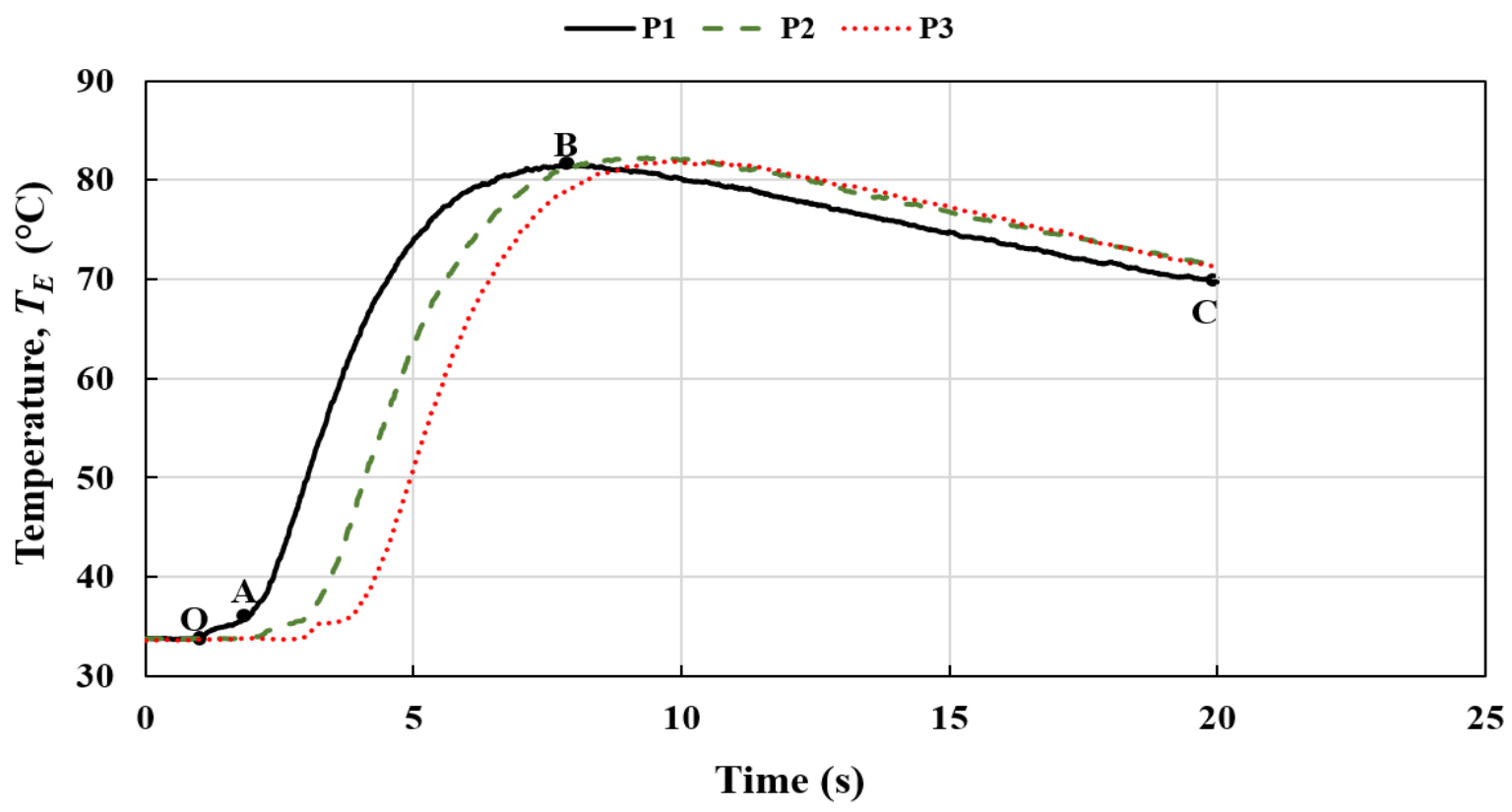

Fig. 11 Variation of the upper surface temperature of $P C$ with time at three different laser beam positions at the P1, P2, and $\mathrm{P} 3$ for $P=100 \mathrm{~W}$ and $V=600 \mathrm{~mm} / \mathrm{min}$.

\subsection{Validation of numerical model and prediction of interface temperature}

The temperature of the top surface of PC is measured by IR technique and compared it with the simulation temperature to verify the numerical model. The variation of the top surface temperature of polycarbonate at the center with power and scanning speeds and the comparison between numerical and experimental results are shown in Fig. 12. The data measured by 
simulation is nearly closed to the experiment and fits very well with $\mathrm{R}^{2}(97.5 \%)$ value approximate unity as shown in Fig. 13. The temperature at the surface increases in a smaller value initially at the time of laser irradiates over the surface and further increases due to thermal conduction. This is also observed in the simulation at $P=100 \mathrm{~W}$ and $V=400 \mathrm{~mm} / \mathrm{min}$, as shown in Fig 14. In the numerical simulations, the temperature rise in the irradiation time zone (OA) is higher than in experiments, but it has obtained the peak temperature in nearly the same time.

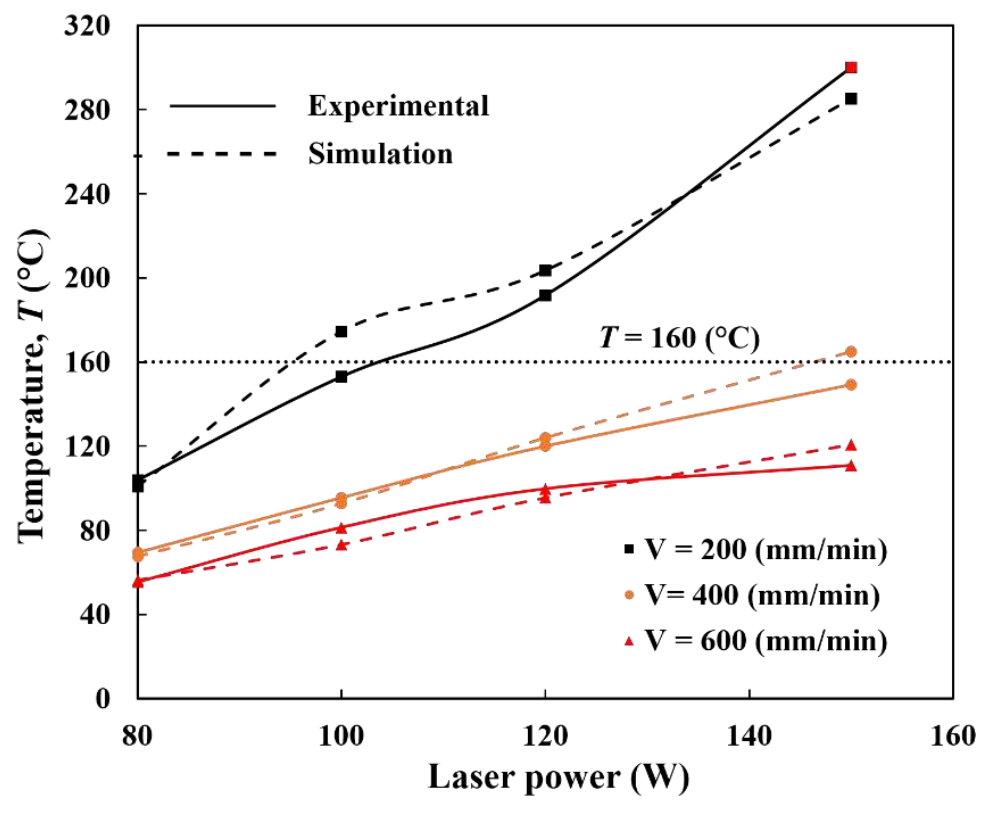

(a)

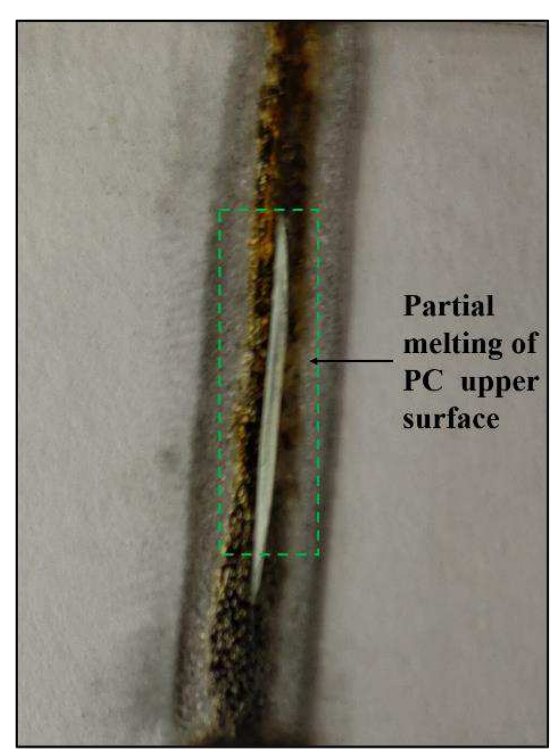

(b)

Fig. 12 Variation of top surface temperature at the center of PC with power at different cutting speeds in experiment and simulation (b) upper PC surface at $P=120 \mathrm{~W}$ and $V=200$ $\mathrm{mm} / \mathrm{min}$.

The numerical model predicts the upper surface temperature at centre with a fine accuracy with an average error of less than $6 \%$. An increase in error is observed (10-14\%) in predicting the temperature when the surface temperature is reached above the glass transition temperature $\left(150{ }^{\circ} \mathrm{C}\right)$ of PC. There may be several reasons for the error in estimating upper surface temperature, such as assumptions follow in the development of the FE model. Furthermore, the effect of temperature-dependent emissivity in IR is not considered; melt flow and its properties such as solidus and liquidus temperature are not considered in the numerical model. Partial melting of top PC surface at power, $P=120 \mathrm{~W}$ and scanning speed, $V=200 \mathrm{~mm} / \mathrm{min}$ and temperature in simulation is near to flow temperature of PC also confirm the validation of the numerical model. 


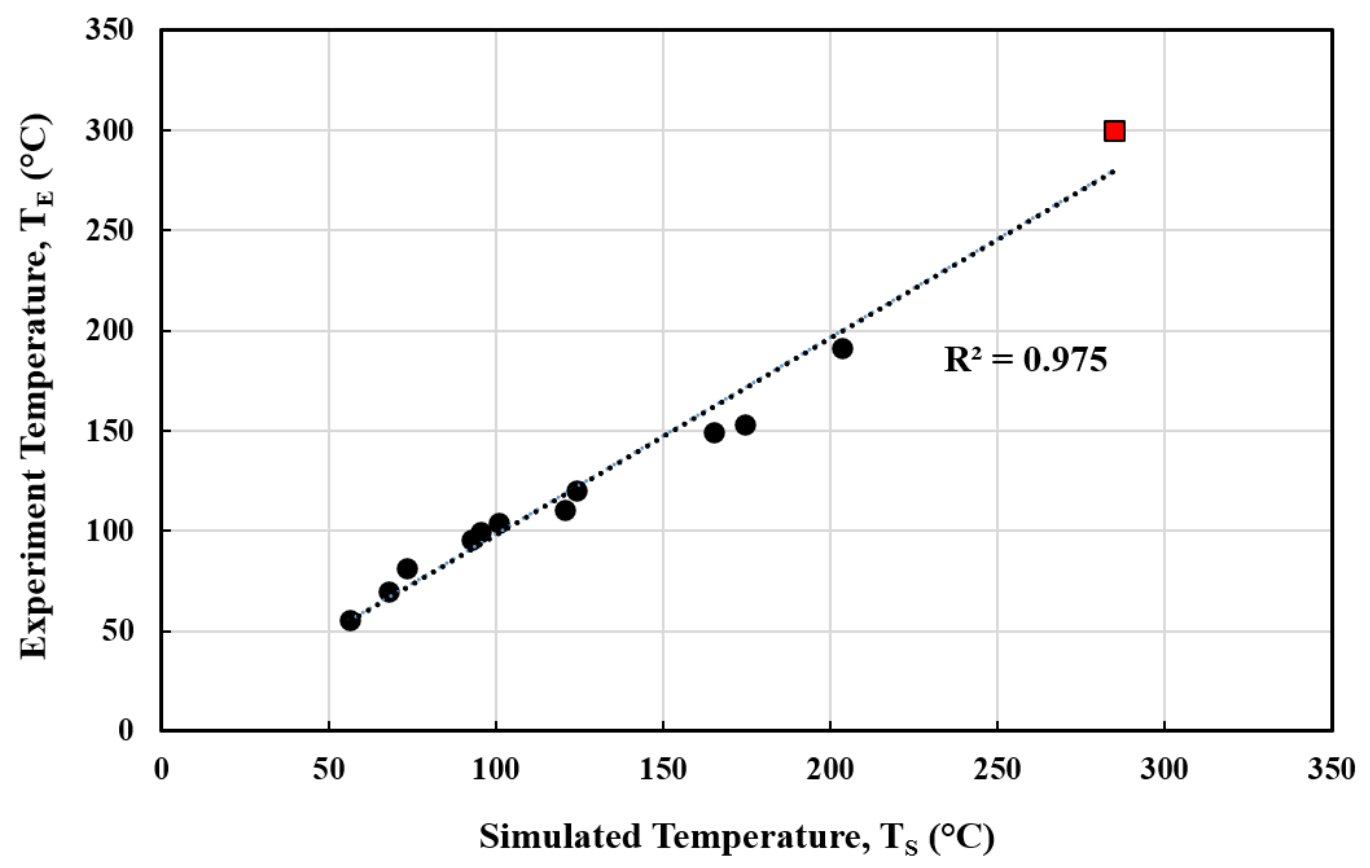

Fig. 13 Comparison of experimental and FE-based model predicted temperature of PC surface.

After validation of the numerical model, the temperature at the interface is predicted by the numerical model with line energy as shown in Fig. 15. Line energy is the ratio of power to the scanning speed. At low line energy, the temperature at the interface is above the glass transition but lower than the flow temperature of polycarbonate. As the line energy increases from 8 $\mathrm{J} / \mathrm{mm}$ to $15 \mathrm{~J} / \mathrm{mm}$, it reaches near the degradation temperature of PC. 


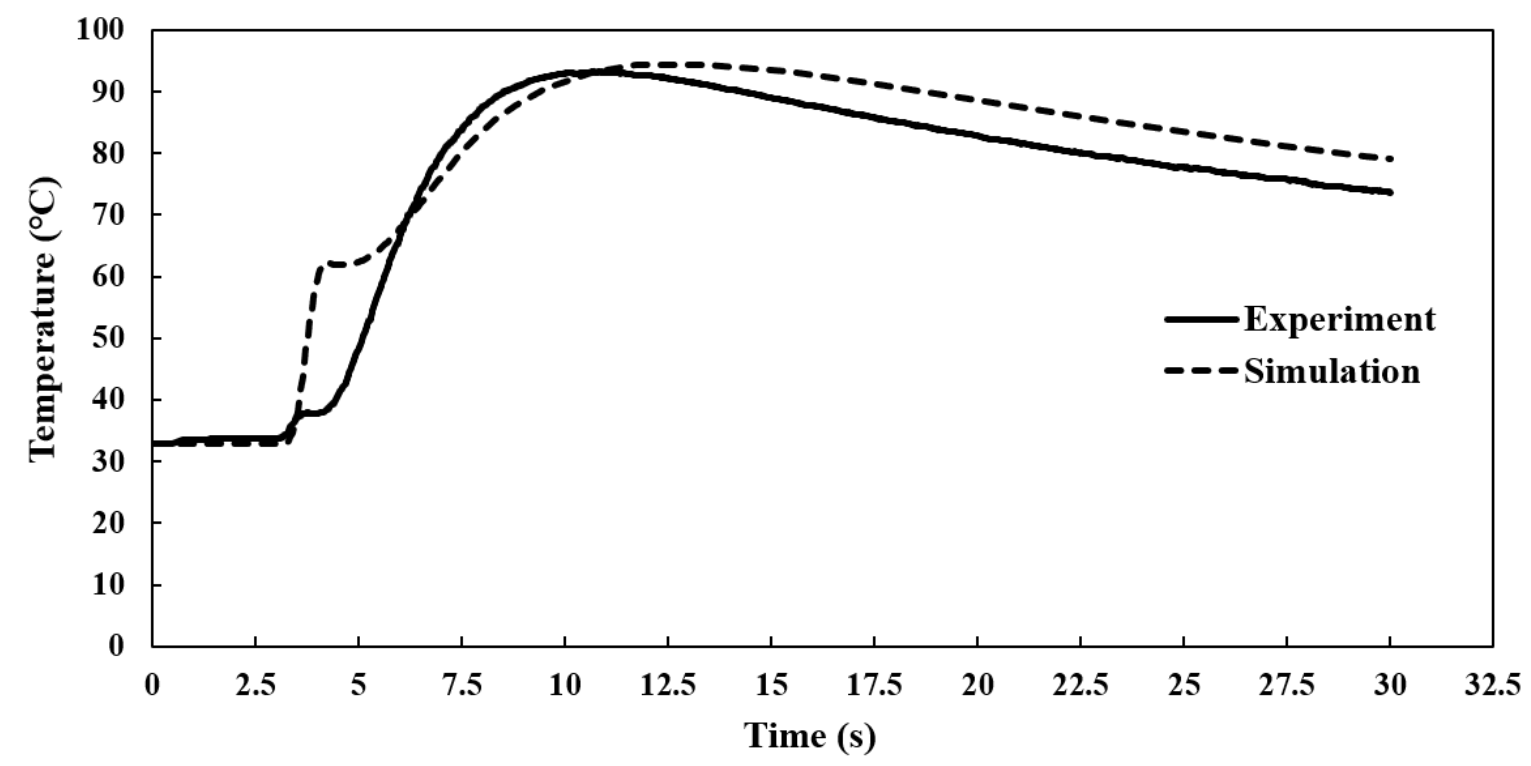

Fig. 14 Comparison of experimental and simulated Top surface temperature at center with time at $P=100 \mathrm{~W}$ and $V=600 \mathrm{~mm} / \mathrm{min}$.

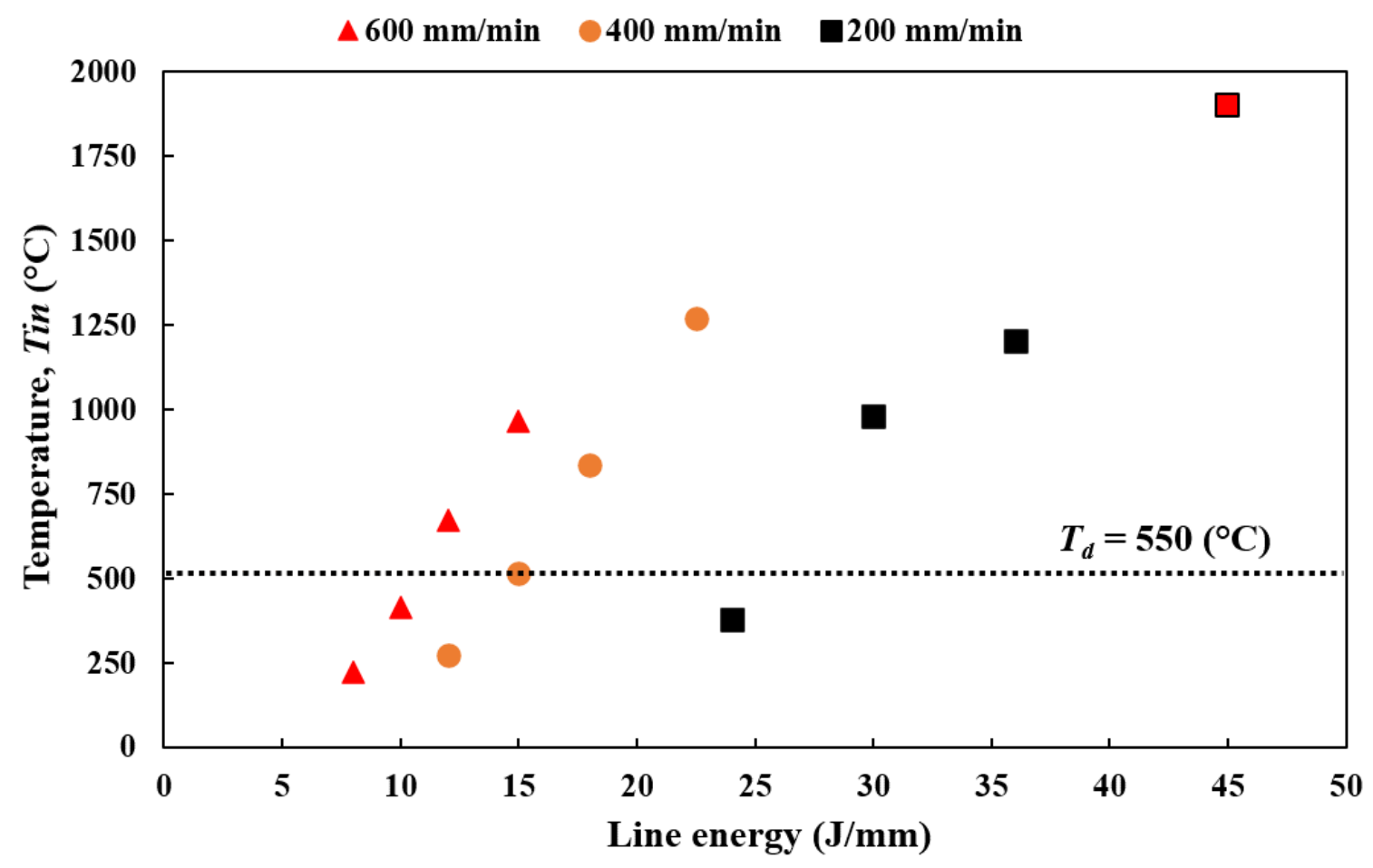

Fig. 15 Variation of interface temperature with line energy.

It is observed that an increase in line energy above $15 \mathrm{~J} / \mathrm{mm}$ by increasing the laser power at constant scanning speed and increases the interface temperature above the degradation temperature of polycarbonate. The degradation of the PC specimen at the center of the joint can be confirmed from Fig. 9 and Fig. 12(b). The degradation temperature of a thermoplastic 
is dependent on the heating rate(Lambiase \& Genna, 2020). The combination of high laser power and low scanning speed generates enormous energy per unit length at the interface. A high temperature is maintained in the joining interface for a long time over a large area, as shown in Fig. 9, which leads to the degradation of polymers.

\section{Conclusions}

This study deals with the development of a new integrated hybrid methodology for the estimation of interface temperature and absorptivity based on inverse analysis technique in laser transmission welding. This methodology is more robust as the FEM-based numerical model is validated with experimental results by comparing weld width with tuned absorptivity and further by comparing the surface temperature with infrared thermography. The variation in heat flux with stand-off distance is also incorporated in the model to achieve more accurate computational results. The developed numerical model is validated with the experimental results, which shows good accuracy with $\mathrm{R}^{2}=97.5 \%$, with an average error of less than $6 \%$. The proposed hybrid technique predicts that the absorptivity is independent of scanning speed at low laser power. But, at high laser power, the absorptivity changes significantly with scanning speed. This approach is also suitable for estimating the absorptivity of the absorbers used in laser transmission welding and other laser-based manufacturing processes such as laser cladding, laser-based additive manufacturing, and laser welding. The accurate estimation of absorptivity also serves the purpose of estimating interface temperature at the joining interface and indicates that the interface temperature increases with line energy.

\section{References}

Acherjee, B. (2021a). Laser transmission welding of dissimilar plastics: 3-D FE modeling and experimental validation. Welding in the World. https://doi.org/10.1007/s40194-02101079-2

Acherjee, B. (2021b). Laser transmission welding of polymers - A review on welding parameters, quality attributes, process monitoring, and applications. Journal of Manufacturing Processes, 64(February), 421-443. https://doi.org/10.1016/j.jmapro.2021.01.022

Acherjee, B., Kuar, A. S., Mitra, S., \& Misra, D. (2012). Modeling of laser transmission contour welding process using FEA and DoE. Optics \& Laser Technology, 44, 12811289. https://doi.org/10.1016/j.optlastec.2011.12.049 
Becker, F., \& Potente, H. (2002). A step towards understanding the heating phase of laser transmission welding in polymers. Polymer Engineering and Science, 42(2), 365-374. https://doi.org/10.1002/pen.10954

Horn, W. (2009). A Progressive Laser Joining Method: Online Process Control With Pyrometer and Galvo Scanner. Laser Technik Journal, 6(1), 42-43. https://doi.org/10.1002/latj.200990008

Ilie, M., Kneip, J., Matte1, S., Roze, C., \& Girasole, T. (2007). Through-transmission laser welding of polymers - temperature field modeling and infrared investigation. Infrared Physics \& Technology, 51, 73-79. https://doi.org/10.1016/j.infrared.2007.02.003

Kant, R., \& Joshi, S. N. (2016). Numerical and experimental studies on the laser bending of magnesium M1A alloy. Lasers in Engineering, 35(1-4), 39-62.

Lambiase, F., \& Genna, S. (2020). Homogenization of temperature distribution at metalpolymer interface during Laser Direct Joining. Optics and Laser Technology, 128(December 2019). https://doi.org/10.1016/j.optlastec.2020.106226

Liu, M., Ouyang, D., Li, C., Sun, H., \& Ruan, S. (2018). Effects of Metal Absorber Thermal Conductivity on Clear Plastic Laser Transmission Welding. Chinese Physics letter, 35, 104205. https://doi.org/10.1088/0256-307X/35/10/104205

Liu, M., Ouyang, D., Zhao, J., Li, C., Sun, H., \& Ruan, S. (2018). Clear plastic transmission laser welding using a metal absorber. Optics and Laser Technology 105 (2018) 242-248. https://doi.org/10.1016/j.optlastec.2018.02.047

Mahmood, T., Mian, A., Amin, M. R., Auner, G., Witte, R., Herfurth, H., \& Newaz, G. (2007). Finite element modeling of transmission laser microjoining process. Journal of Materials Processing Technology, 186, 37-44. https://doi.org/10.1016/j.jmatprotec.2006.11.225

Mayboudi, L. S., Birk, A. M., Zak, G., Bates, P. J., Birk, A. M., Zak, G., A Three-Dimensional Thermal Finite Element Model of Laser Transmission Welding for Lap-Joint, International Journal of Modelling and Simulation, 29:2, 149-155, DOI: 10.1080/02286203.2009.11442520.

Pereira, A. B., Fernandes, F. A. O., Morais, A. B. De, \& Quintão, J. (2019). Mechanical Strength of Thermoplastic Polyamide Welded by Nd: YAG Laser. Polymers, 11, 1-8. https://doi.org/10.3390/polym11091381 
Sooriyapiragasam, S. K., \& Hopmann, C. (2016). Modeling of the heating process during the laser transmission welding of thermoplastics and calculation of the resulting stress distribution. Weld World, 60, 777-791. https://doi.org/10.1007/s40194-016-0330-z

Speka, M., Matte1, S., Pilloz, M., \& Ilie, M. (2008). The infrared thermography control of the laser welding of amorphous polymers. NDT\&E International 41, 178-183. https://doi.org/10.1016/j.ndteint.2007.10.005

Ven, J. D. Van De, \& Erdman, A. G. (2007). Laser Transmission Welding of Thermoplastics - Part I : Temperature and pressure modeling. Journal of Manufacturing Science and Engineering, 129, 849-858. https://doi.org/10.1115/1.2752527

Villar, M., Garnier, C., Chabert, F., Nassiet, V., Samélor, D., Diez, J. C., Sotelo, A., \& Madre, M. A. (2018). In-situ infrared thermography measurements to master transmission laser welding process parameters of PEKK. Optics and Lasers in Engineering, 106, 94-104. https://doi.org/10.1016/j.optlaseng.2018.02.016

Wang, C., Liu, H., Chen, Z., Zhao, D., \& Wang, C. (2021). A new finite element model accounting for thermal contact conductance in laser transmission welding of $\begin{array}{lllll}\text { thermoplastics. } \quad \text { Infrared } & \text { Physics }\end{array}$ https://doi.org/10.1016/j.infrared.2020.103598 